Ciencia, Ambiente y Clima, Vol. 4, No. 1, enero-junio, 2021 • ISSN (impreso): 2636-2317• ISSN (en línea): 2636-2333

DOI: https://doi.org/10.22206/cac.2021.v4i1.pp35-36

\title{
GUÍA ECOTURÍSTICA DEL SISTEMA NACIONAL DE REPÚBLICA DOMINICANA
}

\section{Julia Matilde Mota}

Escuela de Biología. Facultad de Ciencias. Universidad Autónoma de Santo Domingo. Santo Domingo, República

Dominicana. ORCID: 0000-0002-6045-5184, Correo-e: jmota64@uasd.edu.do

Recibido: $12 / 6 / 2020 \bullet$ Aprobado: 21/6/2021

Cómo citar: Mota, J. M. (2021). Guía Ecoturística del Sistema Nacional de República Dominicana. Ciencia, Ambiente y Clima, 4(1), 35-36. DOI: https://doi.org/10.22206/cac.2021.v4i1.pp35-36

En el mes de febrero del año en curso la Academia de Ciencias de la República Dominicana puso en circulación el libro Guía Ecoturística del Sistema Nacional de Áreas Protegidas de República Dominicana, de las autorías de Adolfo López Belando -geógrafo especializado en prehistoria, arqueología, arte rupestre y arqueología submarina- y José Manuel Mateo Feliz, ingeniero agrónomo, con un vasto conocimiento en temas ligados al manejo, la gestión y la planificación en áreas protegidas. Ambos autores han realizado numerosas publicaciones relacionadas con las áreas silvestres y protegidas.

En esta ocasión publican una guía de 332 páginas con ilustraciones de mapas, fotos de paisajes, flora, fauna y otros recursos relevantes de 94 áreas protegidas clasificadas dentro de nueve categorías de manejo del Sistema Nacional de Áreas Protegidas de la República Dominicana. Estas áreas poseen entre sus objetivos de creación: la investigación, la educación y la recreación de los visitantes en zonas de uso público, con infraestructuras y actividades definidas y reguladas por el ministerio, donde se

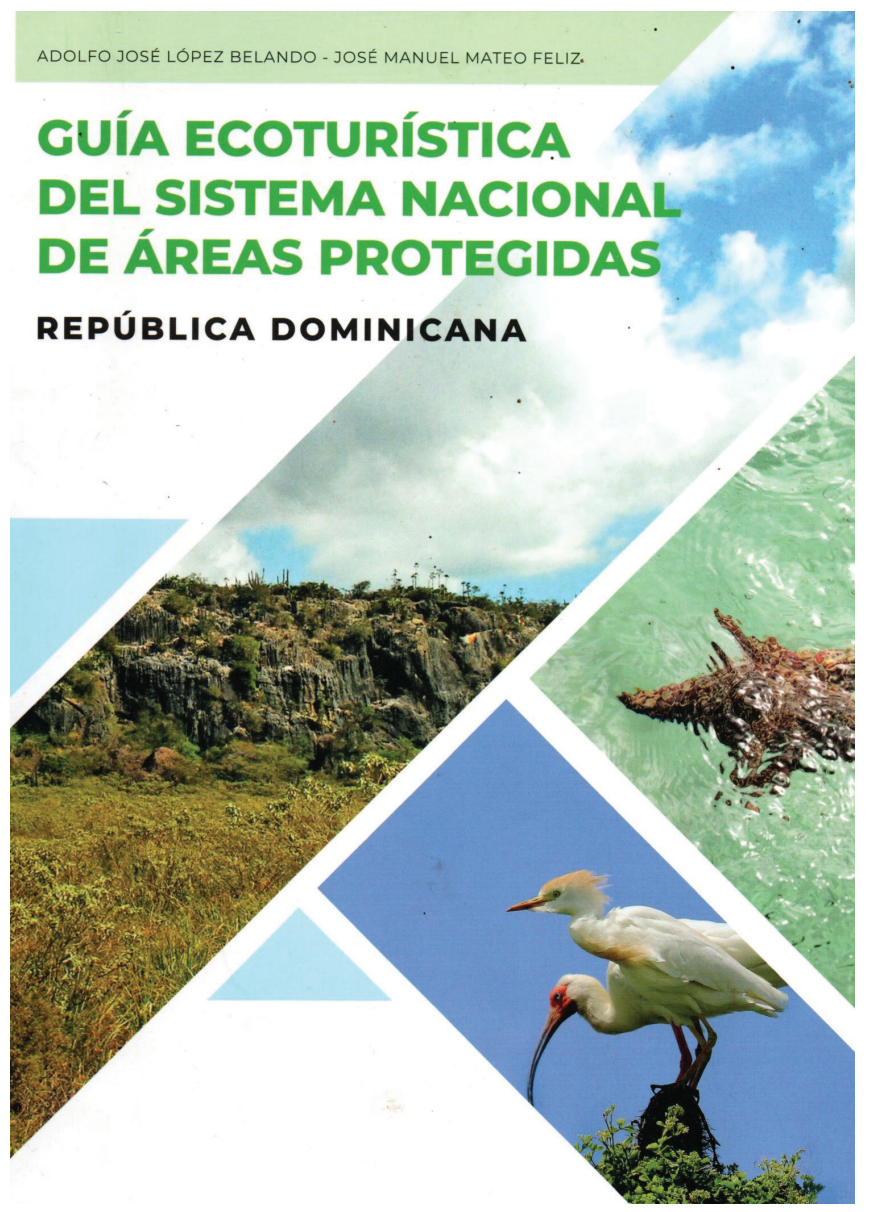


puede disfrutar de servicios ambientales, bellezas escénicas y actividades recreativas sanas y compatibles con los fines de conservación del área, como caminatas en senderos, navegación, visitas a cuevas y cabalgatas, entre otras. Todas esas actividades serán realizadas bajo los preceptos del ecoturismo y la consecuente participación comunitaria.

El libro inicia con una introducción con generalidades acerca de las áreas protegidas, las funciones, la definición y los objetivos de las distintas categorías de manejo, las respectivas extensiones de las 94 áreas protegidas, así como el concepto de uso público y las normativas de visitación.

Más adelante, prosigue con la clasificación de las áreas por categorías de manejo y en cada una de ellas los autores realizan un breve resumen de sus objetivos de creación y datos relevantes. Luego, en orden, describen: localización, accesos -tomando como referencia la ciudad de Santo Domingo-, origen y creación, geología, hidrología, climatología, recursos naturales y culturales, uso público y servicios. Además, como complemento, incluyen un mapa de localización del área en la región y un listado de las infraestructuras y las actividades ecoturísticas que se pueden realizar en sus zonas de uso público.

Consideramos que esta nueva publicación incentiva la visitación a las áreas protegidas para que visitantes nacionales y extranjeros obtengan el conocimiento, la valorización y la recreación a través de las bondades que nos ofrecen sus servicios ambientales, paisajes y recursos culturales tangibles e intangibles asociados; además, se enmarca como una alternativa para reactivar el turismo interno bajo la modalidad del ecoturismo, promoviendo y reactivando la participación activa de los comunitarios e inversionistas del entorno como prestadores de servicios, así como la recaudación de recursos económicos que activarían la economía local.

Esta obra es merecedora de formar parte de bibliotecas personales y de centros educativos, ya que ofrece una información detallada de gran valor, a través de un lenguaje ameno, sencillo y conciso, y podrá ser utilizada como consulta básica sobre las generalidades de las áreas indicadas en la obra, así como material didáctico de apoyo para los estudiantes dominicanos. 